\title{
VIM-positive Pseudomonas aeruginosa in a large tertiary care hospital: matched case- control studies and a network analysis
}

\author{
Anne F. Voor in 't holt', Juliëtte A. Severin', Margot B. H. Hagenaars', Inge de Goeij', Diederik Gommers²
} and Margreet C. Vos ${ }^{1 *}$

\begin{abstract}
Background: Emergence of multidrug-resistant Pseudomonas aeruginosa is of global concern. We aimed to identify epidemiological relationships, the most common way of transmission, and risk factors for presence of Verona Integronencoded Metallo- $\beta$-lactamase (VIM)-positive $P$. aeruginosa (VIM-PA).

Methods: We conducted a network analysis and matched case-control studies (1:2:2). Controls were hospitalbased and matched with cases for ward, day of admission (control group 1 and 2) and time between admission and the identification of VIM-PA (control group 1). The network was visualized using Cytoscape, and risk factors were determined using conditional logistic regression.

Results: Between August 2003 and April 2015, 144 case patients and 576 control patients were recruited. We identified 307 relationships in 114 out of these 144 patients, with most relationships (84.7\%) identified at the same department $<3$ months after a previous case patient was discharged. In the multivariable model, having undergone $\geq 1$ gastroscopy (odds ratio $[\mathrm{OR}]=4.40,95 \%$ confidence interval $[\mathrm{Cl}]=2.00$ to 9.65 and $\mathrm{OR}=2.47 ; 95 \% \mathrm{Cl}=1.12$ to 5.49$),>10$ day use of selective digestive tract decontamination (SDD) $(\mathrm{OR}=2$. 97; $95 \% \mathrm{Cl}=1.02$ to 8.68 and $\mathrm{OR}=4.61 ; 95 \% \mathrm{Cl}=1.22$ to 17.37$)$, and use of quinolones $(\mathrm{OR}=3.29 ; 95 \%$ $\mathrm{Cl}=1.34$ to 8.10 and $\mathrm{OR}=3.95 ; 95 \% \mathrm{Cl}=1.13$ to 13.83 and $\mathrm{OR}=4.47 ; 95 \% \mathrm{Cl}=1.75$ to 11.43 ) were identified as risk factors when using both control groups.

Conclusions: The network analysis indicated that the majority of transmissions occurred on the wards, but through unidentified and presumably persistent sources, which are most likely in the innate hospital environment. Previous use of certain antibiotic regimens made patients prone to VIM-PA carriage. Additionally, gastroscopy could be considered as a high-risk procedure in patients with risk factors. Our results add to the growing body of evidence that infection control measures targeting VIM-PA should be focused on reducing antibiotics and eliminating sources in the environment.
\end{abstract}

Keywords: VIM carbapenemase, Case-control study, Pseudomonas aeruginosa, Network analysis, Infection prevention and control

\footnotetext{
* Correspondence: m.vos@erasmusmc.nl

${ }^{1}$ Department of Medical Microbiology and Infectious Diseases, Erasmus MC

University Medical Centre, Rotterdam, The Netherlands

Full list of author information is available at the end of the article
} 


\section{Background}

The emergence of multidrug-resistant strains of Pseudomonas aeruginosa (MDRPA) is of global concern $[1,2]$. Infections with this resistant microorganism lead to increased morbidity and mortality in patients; especially in specific patient groups, such as those in intensive care units [3-6]. MDRPA hospital outbreaks are mostly caused by MDRPA which produce carbapenemases, with as most clinically significant the metallo- $\beta$-lactamases (MBL) [2]. Currently, the Verona Integron-encoded MBL (VIM) is the most widespread MBL in P. aeruginosa [2, 7-9]. Sources are often hard to eradicate because $P$. aeruginosa is known to form a biofilm in environmental niches which protects it from cleaning and disinfection actions $[10,11]$.

Since 2003, a VIM-positive clone of $P$. aeruginosa (VIM-PA) has emerged in our hospital and became entrenched causing multiple episodes of colonizations and infections in patients $[9,12]$. A systematic review published by our research group showed that the leading risk factors for acquiring MDRPA were carbapenem use and having medical devices [13]. However, risk factors are likely to be outbreak specific because of different local circumstances and patient populations.

The aim of this study was first to identify epidemiological relationships between patients with a VIM-PA, and to identify the most common way of transmission. Second, we aimed to identify risk factors for presence of VIM-PA among colonized and/or infected patients with a case-control study. When a case-control study is used to understand an outbreak, it is often not clear what the best control group is. Both under- and overmatching may affect the results; in essence, the choice of the control determines the outcome. Therefore, our third aim was identifying the most appropriate control group.

\section{Methods}

\section{Ethics statement}

Written approval to conduct this study was received from the medical ethics research committee of the Erasmus MC University Medical Centre (Erasmus MC), Rotterdam, the Netherlands (MEC-2015-240). This study is registered in the Dutch National Trial Register (NTR5145).

\section{Setting}

This retrospective study was conducted at the Erasmus MC in Rotterdam, the Netherlands, using data from August 2003 until April 2015. In this 1200-bed university hospital all medical specialties are available; organized into 48 departments. The Department of Adult Intensive Care (adult ICU) comprises of three high-level ICU wards, and each ward has only single-patient rooms. At the ICU, patients expected to be on a mechanical ventilator for $>48 \mathrm{~h}$ or anticipated to be admitted to the ICU for $>72 \mathrm{~h}$ receive selective digestive tract decontamination (SDD). The SDD regimen is identical to the regimen used by de Smet et al., including 4 days of cefotaxime intravenously [14]. The total number of clinical admissions and clinical admission days from 2003 until 2015 are available in Additional file 1.

\section{Patient inclusion and microbiological analysis}

Patients were included if identified with VIM-PA between $48 \mathrm{~h}$ after admittance to and $48 \mathrm{~h}$ after discharge from a department in the main Erasmus MC building. Patients were excluded if admitted only to the Erasmus MC Sophia Children's Hospital or only to the Erasmus MC Cancer Institute. These buildings are physically separated from the main building, and have their own employees. To our knowledge, there has been no cross-over of VIM-PA to and from these separate buildings. In addition, 22 patients that were involved in an outbreak resulting from a contaminated duodenoscope used for endoscopic retrograde cholangiopancreatography were excluded. The exact cause, source and transmission route were known and it was therefore investigated and reported separately [15].

Cultures taken for clinical diagnostic purposes were processed in the laboratory using standard microbiological methods. In case of suspected growth of carbapenemase-producing $P$. aeruginosa or MDRPA, an in-house polymerase chain reaction (PCR) for detection of $b l a_{\mathrm{VIM}}$ on LightCycler 480 (Roche Diagnostics, Almere, The Netherlands) was performed using previously reported primers [9, 12]. For screening for VIM-PA, swabs were obtained from throat and rectum, cultured overnight at $35{ }^{\circ} \mathrm{C}$ in a Tryptic Soy Broth with ceftazidime $(2 \mathrm{mg} / \mathrm{L})$ and vancomycin $(50 \mathrm{mg} / \mathrm{L})$, followed by our in-house PCR test on the broth. Positive PCR results were confirmed by subculturing the broth on a blood agar (BD Diagnostics, Breda, The Netherlands); P. aeruginosa growing on this agar plate was subjected to blaVIM PCR. Identification and susceptibility testing was performed using Vitek2 (bioMérieux, Marcy l'Etoile, France). Since January 2013, the MALDI-TOF (Bruker Daltonics, Bremen, Germany) was used for identification. Clonal relatedness of VIM-PA from clinical and screening cultures was determined using the DiversiLab system with the Pseudomonas kit (bioMérieux).

General infection prevention and control measures were installed after each case was identified (e.g. isolation). However, in 2011 these measures were intensified; at two adult intensive care units (ICUs), twice-weekly screening for VIM-PA (i.e. rectum and throat cultures) was implemented from October 2011. However, after April 2014, this was reduced to once a week. After August 2014, the weekly screening halted; however, was 
re-implemented in September 2014 because a new case of VIM-PA was identified from a clinical sample. Additionally, at the ICU rectum and throat cultures on VIM are taken upon admittance and discharge of patients. At the neurological high care ward, screening took place once a week from August 2013 until January 2016.

\section{Network analysis}

Admission histories in time and department/room location of patients identified with VIM-PA were retrieved to define epidemiological relatedness. Each identified relation was classified in one out of four categories (Table 1). Then, the data were imported into Cytoscape v3.2.1 (http://www.cytoscape.org) and the network was visualized [16]. It was analysed whether a patient only 'received', only 'transmitted', or 'received and transmitted' the VIM-PA following the definitions in Table 1. "Only received" indicated that a patient did not have epidemiological links to patients identified with a VIM-PA at a later time, "only transmitted" indicated that a patient did not have epidemiological links to patients identified with a VIM-PA earlier in time. "Received and transmitted" indicated that a patient had epidemiological relationships to patients identified with VIM-PA earlier in time and later in time.

\section{Case-control studies}

The risk factor analysis was performed in individual matched retrospective case-control studies, using a 1:2:2 ratio, with hospital-based controls. All information was extracted from the electronic medical records. A list of all patient and treatment related variables collected for cases and controls is presented in Additional file 2.

\section{Control groups}

Patients in control group 1 and 2 were matched for the following three characteristics: I: admitted to the same ward where the case supposedly acquired the VIM-PA (i.e. the ward where the patient was admitted $48 \mathrm{~h}$ before the positive culture) (exact match), II: being admitted on the same date as the case (best match), III: having the same days of exposure as the case (i.e. the days between admittance and the date of the first

Table 1 Definitions of epidemiological relatedness

\begin{tabular}{llllll}
\hline & Definite $^{1}$ & Probable & $\begin{array}{l}\text { Possible- } \\
\text { I }\end{array}$ & $\begin{array}{l}\text { Possible- } \\
\text { I Impossible }\end{array}$ \\
\hline $\begin{array}{l}\text { Same patient } \\
\text { room }\end{array}$ & 1 & 1 & 0 & 0 & 0 \\
$\begin{array}{l}\text { Same } \\
\text { department }\end{array}$ & 1 & 1 & 1 & 1 & 0 \\
Same period & 1 & $0^{\text {a }}$ & 1 & $0^{a}$ & $0^{\mathrm{a} / 0 / 1}$ \\
\hline
\end{tabular}

$0=$ no; $1=$ yes, $0^{\text {a }}=<3$ months after previous positive patient was discharged. ${ }^{1}$ Definition definite was not possible at the intensive care units because only single patient rooms are present positive culture with VIM-PA) (best match). If exact matching was not possible - with the exception of ward - exposure time was found to be the most imperative factor. Patients in control group 3 and 4 were matched for the following characteristics: I: admitted to the same ward as the case (exact match), II: admittance on the same date as the case (best match). The control patient had to be free of colonization or infection with VIM-PA. This could be proven either by negative screening cultures or by the absence of clinical cultures with VIM-PA. A control patient could not serve as a control more than two times; within and between the four different control groups. Also, a case patient could never be selected as a control patient.

\section{Statistical analyses}

For continuous variables, means or medians were calculated. For categorical variables, percentages were calculated. The conditional logistic regression model was used in both univariate and multivariable analyses. Univariate analyses were conducted using the COXREG procedure in SPSS version 21 (IBM Corp., Armonk, New York, USA). Characteristics with a $P$-value of $<0.1$ in univariate analysis were included in the multivariable analyses. Treatment variables could be included as 1) use yes/no, 2) use for $0 / 1-3 / \geq 4$ days or 3 ) use for $0 / 1-3 /$ $4-10 / \geq 11$ days. Selection for inclusion in the multivariable model of either category 1, 2 or 3 of a certain antibiotic was based on: 1) >5 patients in present in each group, 2) estimates of the different categories had to show a difference of at least 1 odds ratio (OR). Multivariable analyses were conducted using conditional logistic regression with dynamic ridge penalties in the $\mathrm{R}$ Project for statistical computing version 3.3.1 (Vienna, Austria). Subgroup analyses were performed for ward of acquisition of case patients and matched controls being ICU or being non-ICU, as well as for case patients in clonal clusters as indicated by the typing results. Additionally, analyses were performed between patients in control group $1 \& 2$ and $3 \& 4$. Results were presented as ORs with $95 \%$ confidence intervals (CI). $P$-values $<0.05$ were considered statistically significant. Graphs were created using GraphPad Prism Version 7.01 (GraphPad Software, Inc. CA, USA).

\section{Results}

\section{Included patients}

Out of 166 patients identified with a VIM-PA between August 2003 and April 2015, eight children were excluded because they were admitted only to the Erasmus MC Sophia Children's hospital and one patient was excluded because admitted only to the Erasmus MC Cancer Institute. In addition, 13 patients were excluded because the VIM-PA was identified within $48 \mathrm{~h}$ after 
admission. Ultimately, 144 patients were included in the network analysis and as case patients in the case-control study (Additional file 1). Nineteen different wards of acquisition were identified, including three ICUs (i.e. two general adult ICUs and 1 thoracic ICU). The top five locations of acquisition were the two general adult ICUs (87 patients, 60.4\%), the gastro-intestinal surgical ward (10 patients; 6.9\%), and the gastroenterology and hepatology ward (7 patients, 4.9\%). Typing showed that the VIM-PA of 29 (20.1\%) patients belonged to clonal cluster A, 105 (72.9\%) to clonal cluster B, 7 (4.9\%) did not belong to clonal cluster $\mathrm{A}$ or $\mathrm{B}$, and it was not possible to type strains from three patients $(2.1 \%)$.

\section{Network analysis}

From 2003 until 2015, we identified 307 relationships in 114 out of 144 patients (Table 1, Fig. 1). Thirty out of 144 patients did not have relationships to other case patients (20.8\%). When considering the definitions (Table 1) we identified nine probable relationships, 38 possible-I relationships and 260 possible-II relationships at 12 different departments. Most relationships (92\%) were identified at the ICU. Twenty-five patients (17.4\%) only 'received' the VIM-PA, 22 (15.3\%) only 'transmitted' VIM-PA and 67 (46.5\%) 'received and transmitted' VIMPA.

\section{Case-control studies \\ Matching}

It was impossible to perfectly match all cases to four controls. Overall, perfect matching was achieved in $38.2 \%$ (range: $16.0 \%-66.0 \%$ ). For cases, the median days from admission to acquisition of VIM-PA was 14 days (range: 1-114 days). In the control groups, the median error in days was $4,4,-1$ and -1 days respectively. Seventeen patients served two times as control patient between the four control groups (11.8\%).

\section{Risk factors for acquisition}

Patient related clinical variables with crude odds ratios, 95\% CI and $P$-values are presented in Table 2. Compared to control group $1 \& 2$ and control group $3 \& 4$, the median length of admission was significantly longer and the 1 -year mortality rate was significantly higher in case patients (Table 2). Treatment related variables with crude odds ratios, 95\% CI and $P$-values are presented in Table 3 and in Additional file 3. When comparing cases to control group 1\&2, multivariable analysis revealed five risk factors; two patient related clinical risk factors, and three treatment related risk factors (Fig. 2). The highest odds ratio was identified for having undergone $\geq 1$ gastroscopy 6 months prior to the identification of VIM-PA $(\mathrm{OR}=4.40,95 \% \mathrm{CI}=2.00$ to $9.65, P<0.001)$. When comparing cases to control group $3 \& 4$, one patient related clinical protective factor was identified (i.e. malignancies) and one risk factor (i.e. gastroscopy) (Fig. 2). Also, four treatment related risk factors were identified; use of piperacillin/tazobactam, 1-3 day and $>3$ day use of quinolones and $>10$ day use of SDD (Fig. 2). The highest odds ratio was identified for $>10$ day use of SDD $(\mathrm{OR}=4.61,95 \% \mathrm{CI}=1.22$ to $17.37, P=0.024)$. In both case-control studies, previous use of quinolones, use of SDD for $>10$ days, and having undergone $\geq 1$ gastroscopy 6 months prior to the identification of VIM-PA were identified as risk factors, and could therefore be considered robust risk factors.

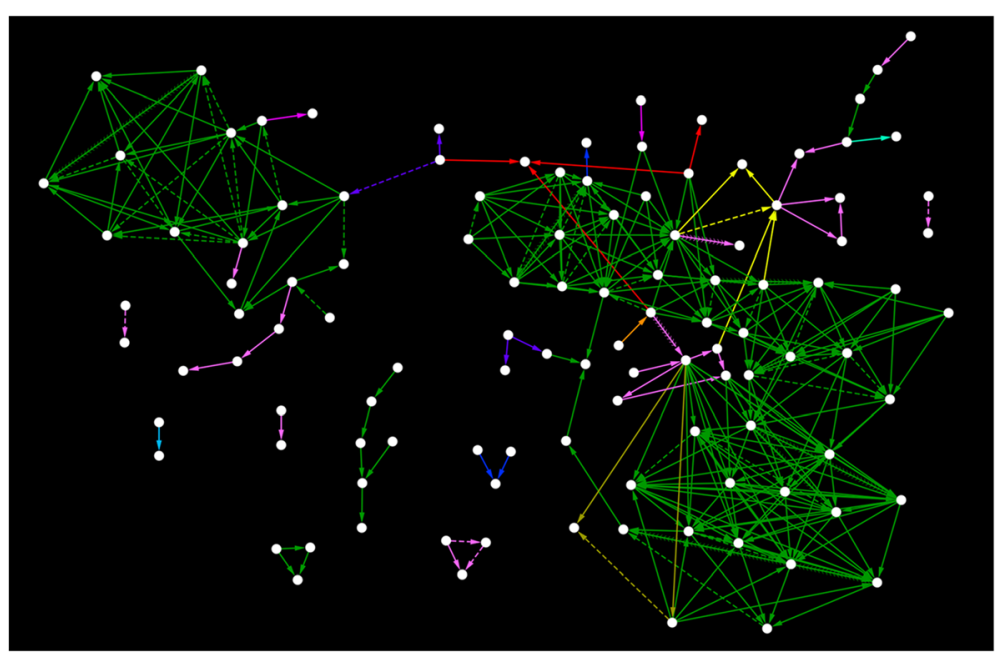

Fig. 1 Network of 307 relationships in 114 out of 144 patients identified with VIM-PA. Thirty out of 144 patients did not have relationships to other case patients (20.8\%). Edge colours represent different Erasmus MC departments; green represents the two adult ICU wards. Line shapes represent the different epidemiological relationships as described in Table 1: contiguous line = probable, dash line $=$ possible $\mathrm{A}$, solid line = possible B. The arrow shows the direction of the relationship 
Table 2 Patient related clinical variables, univariate analyses between cases and controls $1 \& 2$ and between cases and controls $3 \& 4$

\begin{tabular}{|c|c|c|c|c|c|c|c|}
\hline Variables & $\begin{array}{l}\text { Cases } \\
(n=144)\end{array}$ & $\begin{array}{l}\text { Controls } 1 \& 2 \\
(n=288)\end{array}$ & $\begin{array}{l}\text { Crude OR } \\
(95 \% \mathrm{Cl})\end{array}$ & $P$-value & $\begin{array}{l}\text { Controls } 3 \& 4 \\
(n=288)\end{array}$ & $\begin{array}{l}\text { Crude OR } \\
(95 \% \mathrm{Cl})\end{array}$ & $P$-value \\
\hline \multicolumn{8}{|l|}{ Basic characteristics } \\
\hline Age, years, median (range) & $\begin{array}{l}58.3(17- \\
82)\end{array}$ & $60.3(17-92)$ & $\begin{array}{l}0.998 \\
(0.986-0.1010)\end{array}$ & 0.723 & $61.1(17-91)$ & $\begin{array}{l}0.995 \\
(0.982-1.007)\end{array}$ & 0.407 \\
\hline Male gender (\%) & $83(57.6)$ & $174(60.4)$ & $\begin{array}{l}0.886 \\
(0.584-1.345)\end{array}$ & 0.570 & $167(58.0)$ & $\begin{array}{l}0.985 \\
(0.650-1.493)\end{array}$ & 0.944 \\
\hline 28-day mortality (\%) & $41(28.5)$ & $69(24.0)$ & $\begin{array}{l}1.283 \\
(0.804-2.048)\end{array}$ & 0.296 & $40(13.9)$ & $\begin{array}{l}2.677 \\
(1.577-4.544)\end{array}$ & $\begin{array}{l}< \\
0.001\end{array}$ \\
\hline 1-year mortality (\%) & $82(56.9)$ & $95(33.0)$ & $\begin{array}{l}2.680 \\
(1.754-4.094)\end{array}$ & $\begin{array}{l}< \\
0.001\end{array}$ & $63(21.9)$ & $\begin{array}{l}4.950 \\
(3.072-7.976)\end{array}$ & $\begin{array}{l}< \\
0.001\end{array}$ \\
\hline Transferred from another hospital (\%) & $50(34.7)$ & $60(20.8)$ & $\begin{array}{l}2.000 \\
(1.279-3.128)\end{array}$ & 0.002 & $50(17.4)$ & $\begin{array}{l}2.405 \\
(1.530-3.782)\end{array}$ & $\begin{array}{l}< \\
0.001\end{array}$ \\
\hline Median length of admission (range) & $55(3-338)$ & $25(1-258)$ & $\begin{array}{l}1.021 \\
(1.014-1.028)\end{array}$ & $\begin{array}{l}< \\
0.001\end{array}$ & $12(1-1102)$ & $\begin{array}{l}1.021 \\
(1.014-1.027)\end{array}$ & $\begin{array}{l}< \\
0.001\end{array}$ \\
\hline Erasmus MC 1y before VIM-PA (\%) & $64(44.4)$ & $111(38.5)$ & $\begin{array}{l}1.278 \\
(0.851-1.920)\end{array}$ & 0.237 & $109(37.8)$ & $\begin{array}{l}1.348 \\
(0.881-2.064)\end{array}$ & 0.169 \\
\hline Erasmus MC ICU 1y before VIM-PA (\%) & $14(9.7)$ & $15(5.2)$ & $\begin{array}{l}1.867 \\
(0.901-3.867)\end{array}$ & 0.093 & $14(4.9)$ & $\begin{array}{l}2.131 \\
(0.976-4.652)\end{array}$ & 0.058 \\
\hline Surgery (\%) & $87(60.4)$ & $119(41.3)$ & $\begin{array}{l}2.165 \\
(1.432-3.275)\end{array}$ & $\begin{array}{l}< \\
0.001\end{array}$ & $121(42.0)$ & $\begin{array}{l}2.119 \\
(1.399-3.209)\end{array}$ & $\begin{array}{l}< \\
0.001\end{array}$ \\
\hline \multicolumn{8}{|l|}{ Underlying diseases } \\
\hline Cystic fibrosis (\%) & $2^{\mathrm{a}}(1.4)$ & $3(1.0)$ & NA & NA & $2(0.7)$ & NA & NA \\
\hline Chronic respiratory illness (\%) & $29(20.1)$ & $43(14.9)$ & $\begin{array}{l}1.488 \\
(0.861-2.571)\end{array}$ & 0.155 & $43(14.9)$ & $\begin{array}{l}1.518 \\
(0.868-2.655)\end{array}$ & 0.144 \\
\hline Chronic kidney failure (\%) & $5(3.5)$ & $3(1.0)$ & $\begin{array}{l}3.33 \\
(0.797-13.948)\end{array}$ & 0.099 & $11(3.8)$ & $\begin{array}{l}0.903 \\
(0.304-2.689)\end{array}$ & 0.855 \\
\hline Acute kidney failure; use of CWH (\%) & $28(19.4)$ & $18(6.3)$ & $\begin{array}{l}3.471 \\
(1.844-6.533)\end{array}$ & $\begin{array}{l}< \\
0.001\end{array}$ & $10(3.5)$ & $\begin{array}{l}6.651 \\
(3.022-14.638)\end{array}$ & $\begin{array}{l}< \\
0.001\end{array}$ \\
\hline Chronic liver failure (\%) & $5(3.5)$ & $7(2.4)$ & $\begin{array}{l}1.480 \\
(0.442-4.952)\end{array}$ & 0.525 & $17(5.9)$ & $\begin{array}{l}0.588 \\
(0.217-1.594)\end{array}$ & 0.297 \\
\hline Acute liver failure (\%) & $0(0)$ & $6(2.1)$ & NA & NA & $3(1.0)$ & NA & NA \\
\hline $\begin{array}{l}\text { Chronic problems of the gastrointestinal tract } \\
(\%)\end{array}$ & $19(13.2)$ & $28(9.7)$ & $\begin{array}{l}1.377 \\
(0.758-2.502)\end{array}$ & 0.294 & $26(9.0)$ & $\begin{array}{l}1.603 \\
(0.822-3.126)\end{array}$ & 0.166 \\
\hline Acute problems of the gastrointestinal tract (\%) & $28(19.4)$ & $39(13.5)$ & $\begin{array}{l}1.493 \\
(0.894-2.494)\end{array}$ & 0.126 & $54(18.8)$ & $\begin{array}{l}1.047 \\
(0.627-1.750)\end{array}$ & 0.861 \\
\hline Auto-immune disease (\%) & $7(4.9)$ & $18(6.3)$ & $\begin{array}{l}0.762 \\
(0.308-1.886)\end{array}$ & 0.556 & $26(9.0)$ & $\begin{array}{l}0.520 \\
(0.221-1.223)\end{array}$ & 0.134 \\
\hline Human immunodeficiency virus (\%) & $0(0)$ & $2(0.7)$ & NA & NA & $4(1.4)$ & NA & NA \\
\hline Diabetes (\%) & $24(16.7)$ & $37(12.8)$ & $\begin{array}{l}1.353 \\
(0.776-2.360)\end{array}$ & 0.287 & $48(16.7)$ & $\begin{array}{l}1.000 \\
(0.579-1.726)\end{array}$ & 1.000 \\
\hline Solid organ transplant recipient (\%) & $20^{\mathrm{a}}(14.0)$ & $20(6.9)$ & $\begin{array}{l}2.257 \\
(1.139-4.473)\end{array}$ & 0.020 & $30(10.4)$ & $\begin{array}{l}1.463 \\
(0.784-2.729)\end{array}$ & 0.232 \\
\hline Stem cell/bone marrow transplant recipient (\%) & $7^{\mathrm{a}}(4.9)$ & $6(2.1)$ & $\begin{array}{l}3.562 \\
(0.875-14.493)\end{array}$ & 0.076 & $1(0.3)$ & NA & NA \\
\hline Use of immunosuppressive agents (\%) & $55(38.2)$ & $71(24.7)$ & $\begin{array}{l}1.920 \\
(1.236-2.985)\end{array}$ & 0.004 & $55(19.1)$ & $\begin{array}{l}2.493 \\
(1.602-3.879)\end{array}$ & $\begin{array}{l}< \\
0.001\end{array}$ \\
\hline Malignancies (\%) & $32(22.2)$ & $76(26.4)$ & $\begin{array}{l}0.777(0.472- \\
1.280)\end{array}$ & 0.322 & $92(31.9)$ & $\begin{array}{l}0.570 \\
(0.347-0.936)\end{array}$ & 0.026 \\
\hline Neutropenia, < 500 cells/ $\mu \mathrm{L}(\%)$ & $3^{\mathrm{b}}(2.7)$ & $4^{\mathrm{b}}(2.1)$ & $\begin{array}{l}0.883 \\
(0.159-4.889)^{b}\end{array}$ & 0.886 & $7^{\mathrm{b}}(2.4)$ & $\begin{array}{l}0.667 \\
(0.164-2.713)^{b}\end{array}$ & 0.571 \\
\hline \multicolumn{8}{|l|}{ Endoscopies } \\
\hline Colonoscopy (\%) & $7(4.9)$ & $10(3.5)$ & $\begin{array}{l}1.400 \\
(0.533-3.678)\end{array}$ & 0.495 & $12(4.2)$ & $\begin{array}{l}1.202 \\
(0.432-3.345)\end{array}$ & 0.724 \\
\hline
\end{tabular}


Table 2 Patient related clinical variables, univariate analyses between cases and controls $1 \& 2$ and between cases and controls $3 \& 4$ (Continued)

\begin{tabular}{|c|c|c|c|c|c|c|c|}
\hline Variables & $\begin{array}{l}\text { Cases } \\
(n=144)\end{array}$ & $\begin{array}{l}\text { Controls } 1 \& 2 \\
(n=288)\end{array}$ & $\begin{array}{l}\text { Crude OR } \\
(95 \% \mathrm{Cl}) \\
\end{array}$ & $P$-value & $\begin{array}{l}\text { Controls } 3 \& 4 \\
(n=288)\end{array}$ & $\begin{array}{l}\text { Crude OR } \\
(95 \% \mathrm{Cl}) \\
\end{array}$ & $P$-value \\
\hline Sigmoidoscopy (\%) & $7(4.9)$ & $5(1.7)$ & $\begin{array}{l}2.800 \\
(0.889-8.822)\end{array}$ & 0.079 & $8(2.8)$ & $\begin{array}{l}1.750 \\
(0.635-4.826)\end{array}$ & 0.280 \\
\hline Endoscopic ultrasound (\%) & $7(4.9)$ & $26(9.0)$ & $\begin{array}{l}0.490 \\
(0.202-1.189)\end{array}$ & 0.115 & $19(6.6)$ & $\begin{array}{l}0.684 \\
(0.260-1.802)\end{array}$ & 0.443 \\
\hline Gastroscopy (\%) & $75(52.1)$ & $50(17.4)$ & $\begin{array}{l}6.609 \\
(3.803-11.485)\end{array}$ & $\begin{array}{l}< \\
0.001\end{array}$ & $59(20.5)$ & $\begin{array}{l}4.529 \\
(2.79-7.335)\end{array}$ & $\begin{array}{l}< \\
0.001\end{array}$ \\
\hline ERCP (\%) & $17(11.8)$ & $15(5.2)$ & $\begin{array}{l}2.520 \\
(1.190-5.336)\end{array}$ & 0.016 & $10(3.5)$ & $\begin{array}{l}3.917 \\
(1.678-9.143)\end{array}$ & 0.002 \\
\hline Bronchoscopy (\%) & $41(28.5)$ & $34(11.8)$ & $\begin{array}{l}3.159 \\
(1.841-5.422)\end{array}$ & $\begin{array}{l}< \\
0.001\end{array}$ & $33(11.5)$ & $\begin{array}{l}3.030 \\
(1.800-5.103)\end{array}$ & $\begin{array}{l}< \\
0.001\end{array}$ \\
\hline Transoesophageal Echocardiography (TEE) (\%) & $12(8.3)$ & $13(4.5)$ & $\begin{array}{l}1.846 \\
(0.842-4.046)\end{array}$ & 0.126 & $13(4.5)$ & $\begin{array}{l}1.901 \\
(0.849-4.257)\end{array}$ & 0.118 \\
\hline \multicolumn{8}{|l|}{ Medical devices } \\
\hline Mechanical ventilation (\%) & $129(89.6)$ & $210(72.9)$ & $\begin{array}{l}4.921 \\
(2.284-10.600)\end{array}$ & $\begin{array}{l}< \\
0.001\end{array}$ & $185(64.2)$ & $\begin{array}{l}8.211 \\
(3.857-17.481)\end{array}$ & $\begin{array}{l}< \\
0.001\end{array}$ \\
\hline Tracheostomy (\%) & $29(20.1)$ & $38(13.2)$ & $\begin{array}{l}1.801 \\
(1.011-3.211)\end{array}$ & 0.046 & $9(3.1)$ & $\begin{array}{l}7.883 \\
(3.443-18.045)\end{array}$ & $\begin{array}{l}< \\
0.001\end{array}$ \\
\hline Extracorporeal membrane oxygenation (\%) & $2(1.4)$ & $0(0)$ & NA & NA & $0(0)$ & NA & NA \\
\hline Central venous catheter (\%) & $103(71.5)$ & $124(43.1)$ & $\begin{array}{l}4.121 \\
(2.477-6.854)\end{array}$ & $\begin{array}{l}< \\
0.001\end{array}$ & $77(26.7)$ & $\begin{array}{l}9.040 \\
(5.101-16.023)\end{array}$ & $\begin{array}{l}< \\
0.001\end{array}$ \\
\hline
\end{tabular}

Abbreviations: VIM-PA Verona Integron-encoded Metallo- $\beta$-lactamase (VIM)-positive Pseudomonas aeruginosa, 95\% CI 95\% confidence interval, y year, ICU intensive care unit, $C V V H$ Continuous Veno-Venous Hemofiltration, ERCP Endoscopic Retrograde Cholangiopancreatography

${ }^{\mathrm{a}} 1$ case missing because no medical background was available

${ }^{b}$ For 32 cases, 99 controls $1 \& 2$ and 108 controls $3 \& 4$ no information about neutrophils was available

bold = statistically significant

Univariate results of the subgroup analyses are presented in Additional files 4 and 5. Multivariable results are displayed in Fig. 3. There are differences in identified risk factors in the different subgroups. For example, for patients with DiversiLab type A endoscopies did not seem to play a role, whereas in type B they did. Also, at the ICU antibiotic use (trimethoprim/sulfamethoxazole) was identified as a risk factor in combination with having undergone $\geq 1$ gastroscopy and bronchoscopy 6 months prior to the identification of VIM-PA, whereas at non-ICU wards it was a combination of having undergone $\geq 1$ gastroscopy 6 months prior to the identification of VIM-PA and surgery or being admitted at the Erasmus MC before.

Univariate differences between control group 1\&2 and $3 \& 4$ are presented in Additional file 6. Multivariable analysis revealed only two differences between the control groups, regarding protection by acute gastrointestinal tract problems and use of nitrofurantoin (Fig. 2).

\section{Discussion}

Our study aimed to identify epidemiological relationships, the most common way of transmission and risk factors for presence of VIM-PA. In the network analysis, we did not identify definite relationship and only nine probable relationships. Therefore, the same patient room, either sharing a patient room or being admitted at the same patient room within 3 months, is not the most likely source. However, there was a relation with the same department. Surprisingly, the same admission period seems not to be important; most relationships were identified within 3 months after the previous positive patient was discharged. Thus, the majority of transmissions occurred on the wards in a wide time frame. Therefore, it must have occurred through unidentified sources, which may be either undetected patients or unidentified sources in the innate environment. Given the fact that patients at the ICUs and neurology high-care ward were frequently screened; we assume that undetected patients are not plausible. Our hypothesis is that persistent sources in the innate environment play an important role in the route of transmission of this pathogen. This is in agreement with current knowledge on the behaviour of this bacterium, as well as previous outbreak reports that identified the environment as source/reservoir $[13,17]$.

The case-control studies showed first that previous use of certain antibiotics were associated with an increased risk of acquisition of VIM-PA; especially the use of quinolones, piperacillin/tazobactam, and trimethoprim/sulfamethoxazole should be avoided if possible. Second, gastroscopy and bronchoscopy were identified 
Table 3 Treatment related variables, univariate analyses between cases and controls $1 \& 2$ and between cases and controls $3 \& 4$

\begin{tabular}{|c|c|c|c|c|c|c|c|}
\hline Variables ${ }^{c}$ & $\begin{array}{l}\text { Cases } \\
\left(n=138^{\mathrm{a}}\right)\end{array}$ & $\begin{array}{l}\text { Controls } 1 \& 2 \\
(n=288)\end{array}$ & $\begin{array}{l}\text { Crude OR } \\
(95 \% \mathrm{Cl})\end{array}$ & $P$-value & $\begin{array}{l}\text { Controls } 3 \& 4 \\
(n=288)\end{array}$ & $\begin{array}{l}\text { Crude OR } \\
(95 \% \mathrm{Cl})\end{array}$ & $P$-value \\
\hline Antifungals (\%) & $82(59.4)$ & $79(28.0)^{b}$ & $\begin{array}{l}4.863 \\
(2.886-8.194)\end{array}$ & $<0.001$ & $50(17.7)^{b}$ & $\begin{array}{l}5.890 \\
(3.647-9.512)\end{array}$ & $<0.001$ \\
\hline Antivirals (\%) & $16(11.6)$ & $19(6.7)^{\mathrm{b}}$ & $\begin{array}{l}1.913 \\
(0.899-4.071)\end{array}$ & 0.092 & $17(6.0)^{\mathrm{b}}$ & $\begin{array}{l}2.053 \\
(1.011-4.169)\end{array}$ & 0.047 \\
\hline Aminoglycosides (\%) & $51(37.0)$ & $53(18.8)$ & $\begin{array}{l}2.988 \\
(1.769-5.046)\end{array}$ & $<0.001$ & $24(8.5)$ & $\begin{array}{l}6.832 \\
(3.692-12.643)\end{array}$ & $<0.001$ \\
\hline Amoxicillin/clavulanic acid (\%) & $39(29.1)$ & $48(17.0)^{b}$ & $\begin{array}{l}2.014 \\
(1.196-3.394)\end{array}$ & 0.009 & $40(14.2)^{b}$ & $\begin{array}{l}2.388 \\
(1.428-3.992)\end{array}$ & 0.001 \\
\hline Carbapenems (\%) & $58(42.0)$ & $58(20.7)$ & $\begin{array}{l}3.124 \\
(1.898-5.142)\end{array}$ & $<0.001$ & $26(9.2)$ & $\begin{array}{l}6.762 \\
(3.810-12.000)\end{array}$ & $<0.001$ \\
\hline Cephalosporins (\%) & $104(77.6)$ & $131(46.5)$ & $\begin{array}{l}3.942 \\
(2.383-6.520)\end{array}$ & $<0.001$ & $107(37.9)$ & $\begin{array}{l}6.407 \\
(3.692-11-121)\end{array}$ & $<0.001$ \\
\hline Colistin (\%) & $17(12.7)$ & $20(7.1)^{\mathrm{b}}$ & $\begin{array}{l}1.896 \\
(0.926-3.880)\end{array}$ & 0.080 & $12(4.3)^{\mathrm{b}}$ & $\begin{array}{l}4.282 \\
(1.756-10.437)\end{array}$ & 0.001 \\
\hline Macrolides (\%) & $60(44.8)$ & $64(22.7)$ & $\begin{array}{l}2.702 \\
(1.696-4.304)\end{array}$ & $<0.001$ & $27(9.6)$ & $\begin{array}{l}6.881 \\
(3.885-12.190)\end{array}$ & $<0.001$ \\
\hline Metronidazole (\%) & $48(35.8)$ & $48(17.0)$ & $\begin{array}{l}2.445 \\
(1.534-3.898)\end{array}$ & $<0.001$ & $32(11.3)^{b}$ & $\begin{array}{l}4.689 \\
(2.630-8.360)\end{array}$ & $<0.001$ \\
\hline Nitrofurantoin (\%) & $17(12.7)$ & $12(4.3)^{b}$ & $\begin{array}{l}3.486 \\
(1.543-7.878)\end{array}$ & 0.003 & $24(8.5)$ & $\begin{array}{l}1.527 \\
(0.767-3.039)\end{array}$ & 0.228 \\
\hline Penicillin (\%) & 29 (21.6) & $49(17.4)$ & $\begin{array}{l}1.226 \\
(0.739-2.032)\end{array}$ & 0.431 & $31(11.0)$ & $\begin{array}{l}2.100 \\
(1.199-3.678)\end{array}$ & 0.009 \\
\hline Piperacillin/tazobactam (\%) & $49(36.6)$ & $50(17.7)^{b}$ & $\begin{array}{l}2.774 \\
(1.666-4.621)\end{array}$ & $<0.001$ & $32(11.3)^{b}$ & $\begin{array}{l}4.572 \\
(2.604-8.025)\end{array}$ & $<0.001$ \\
\hline Quinolones (\%) & $94(70.1)$ & $88(31.2)$ & $\begin{array}{l}6.087 \\
(3.553-10.429)\end{array}$ & $<0.001$ & $53(18.8)$ & $9.193(5.284-15.996)$ & $<0.001$ \\
\hline Trimethoprim/sulfamethoxazole (\%) & $32(23.9)$ & $23(8.2)^{b}$ & $\begin{array}{l}3.606 \\
(1.930-6.740)\end{array}$ & $<0.001$ & $19(6.7)^{\mathrm{b}}$ & $\begin{array}{l}3.834 \\
(2.098-7.007)\end{array}$ & $<0.001$ \\
\hline Vancomycin (\%) & $74(55.2)$ & $51(18.1)$ & $\begin{array}{l}6.355 \\
(3.652-11.057)\end{array}$ & $<0.001$ & $27(9.6)$ & $\begin{array}{l}9.847 \\
(5.437-17.836)\end{array}$ & $<0.001$ \\
\hline Other antibiotics (\%) & $32(23.9)$ & $28(9.9)^{b}$ & $\begin{array}{l}3.074 \\
(1.680-5.627)\end{array}$ & $<0.001$ & $30(10.6)^{b}$ & $\begin{array}{l}2.684 \\
(1.512-4.763)\end{array}$ & 0.001 \\
\hline Selective digestive tract decontamination (\%) & $92(68.7)$ & $109(38.7)$ & $\begin{array}{l}4.583 \\
(2.641-7.952)\end{array}$ & $<0.001$ & $59(20.9)$ & $\begin{array}{l}10.864 \\
(5.748-20.536)\end{array}$ & $<0.001$ \\
\hline
\end{tabular}

Abbreviations: $95 \% \mathrm{Cl} 95 \%$ confidence interval, ${ }^{\mathrm{a}}$ Data on antibiotics of the first six cases was missing, bold = statistically significant, $P$-value $<0.05$. ${ }^{b}$ Included in multivariable analysis. ${ }^{c}$ For categorical data see Additional file 3

as risk factors (Fig. 2). Third, the results of the two different case-control studies were largely in line with each other, with three common risk factors (i.e. previous use of quinolones, use of SDD for $>10$ days, and having undergone $\geq 1$ gastroscopy 6 months prior to the identification of VIM-PA) that could therefore be considered as robust. The assumption would be that certain antibiotics change the normal gut or throat flora in such a way that multidrug-resistant bacteria more easily attach to and colonize either the gut or throat. Nevertheless, multidrug-resistant microorganisms have to be offered to the patient, and this may occur through endoscopic procedures by contaminated endoscopes or using water from a contaminated source. Both the previous use of antibiotics and prior procedures with flexible endoscopes have been highlighted in previous studies as risk factors for acquisition of various multidrug microorganisms, including VIM-PA [18, 19].

The group of antibiotics that favours presence of VIMPA (i.e. increases a patients' susceptibility to acquire VIM-PA) depends on the choice of the control group. Furthermore, we learned that although highly significant factors were obtained with one group of controls, these can disappear when other groups are compared as these groups differ in inclusion criteria or definition; the results highly depend on the choice of the control.

\section{Limitations}

Network analysis

Criteria for epidemiological relationships, especially relationships in time and space, are not clearly defined for outbreaks with multidrug-resistant bacteria. We 


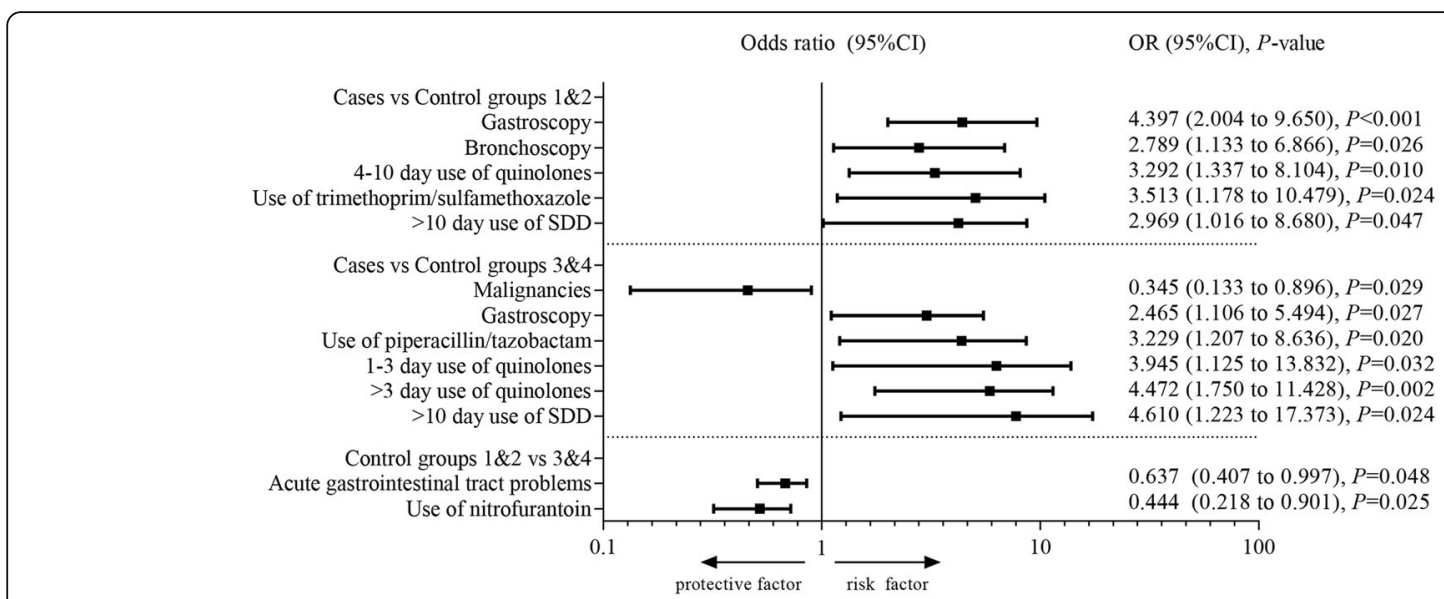

Fig. 2 Risk factors and protective factors identified using multivariable analysis. Abbreviations: SDD = selective digestive tract decontamination, $95 \% \mathrm{Cl}=95 \%$ confidence interval

developed criteria which are easy to apply; however, inherent to this is a simplification of the truth. We propose that these definitions would be modified or extended in case data from future studies warrants.

\section{Case-control studies}

First, this is a single-centre case-control study, which possibly hampers generalizability. Second, matching on ward of acquisition and length of stay prior to the positive culture might have caused additional matching on e.g. comorbidities and disease severity. However, we have done this deliberately. When comparing ICU to non-ICU patients, disease severity and possibly also comorbidities will be risk factors just because the groups are not similar. Third, misclassification of exposure could be present; not all control patients were cultured for VIM-PA, which could lead to VIM-PA carriers present in control group. However, this misclassification if present could only have led to an underestimation of the identified effects. Fourth, perfect matching was only achieved in $38 \%$. This seems low; however, $100 \%$ perfect matching is not possible for large case-control studies including patients who have complicated medical histories and futures. Possibly, the percentage of perfect matching could be added as an item to the STROBE statement [20].

In one of the subgroup analyses, differences were identified between DiversiLab clonal cluster A and B (Fig. 3).

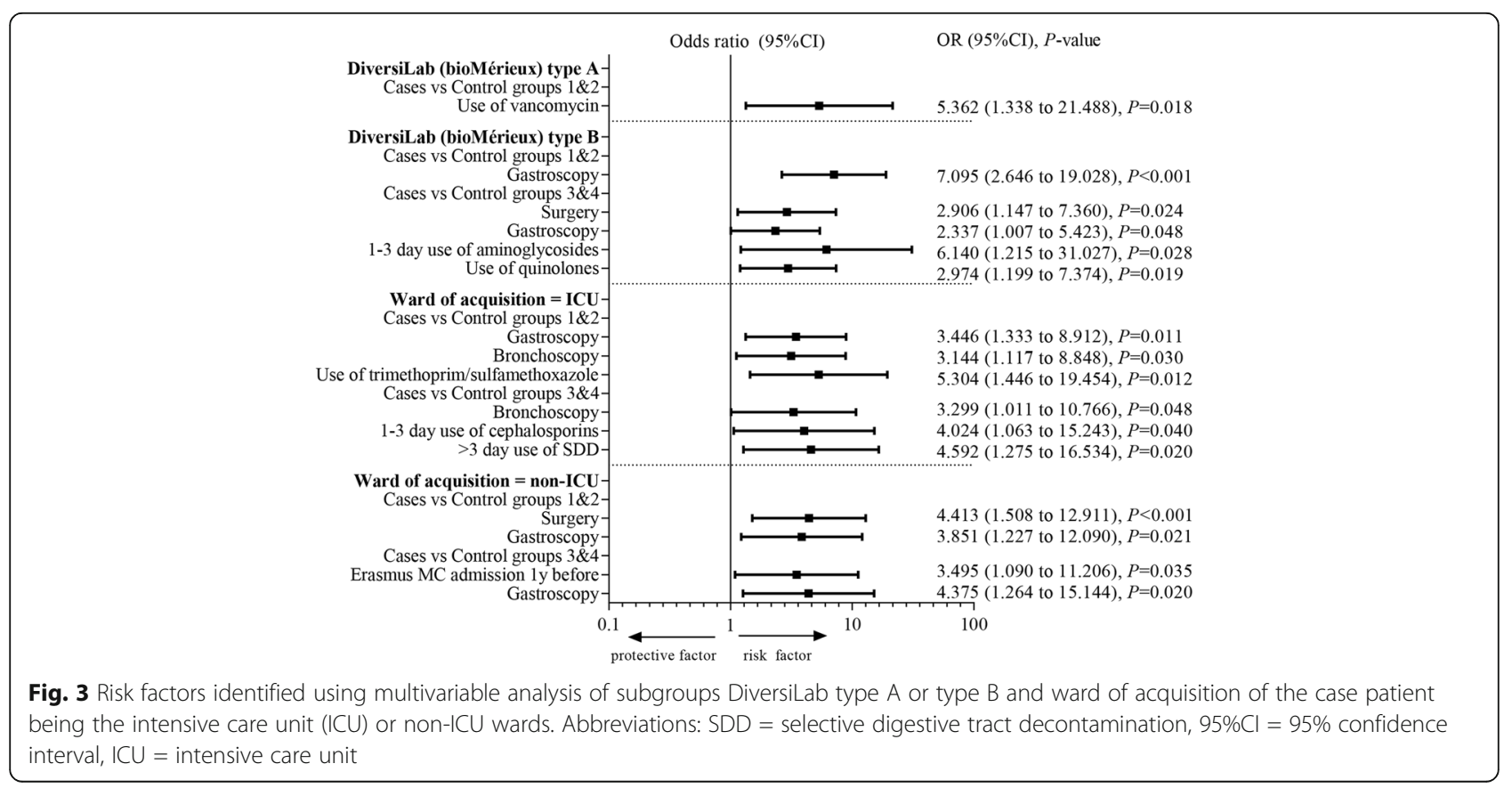


However, although widely applied, the DiversiLab system can be considered a limitation of the study, since available data regarding the DiversiLab system for P. aeruginosa are contradictory. A review by Brossier et al. on the performance of the DiversiLab system for $P$. aeruginosa concluded that the results should be interpreted with caution, and always in combination with epidemiological data, as was done in our study [21].

\section{Conclusion}

The network analysis indicated that the majority of transmissions occurred on the wards, but through unidentified and presumably persistent sources, which are most likely in the innate hospital environment. Previous use of certain antibiotic regimens made patients prone to VIM-PA carriage. Additionally, gastroscopy could be considered as a high-risk procedure in patients with risk factors.

\section{Recommendation}

If there is an outbreak with VIM-PA, we showed that first; the entire ward should be seen as reservoir and as contaminated. Therefore, cleaning and disinfection practices should be installed and possible sources should be eliminated. We also feel that it is especially important to search for unknown reservoirs in the environment. Second, use of particularly quinolones should be avoided because this could make a patient 'prone' for acquiring VIM-PA. Third, we showed that in an outbreak setting gastroscopy and bronchoscopy could be seen as high-risk procedures. Finally, a casecontrol study should be executed to identify outbreak specific risk factors. Because we showed that if you change matching criteria outcomes do differ, it would be advisable to always include multiple definitions for control inclusion.

\section{Additional files}

Additional file 1: Text file: The number of clinical admissions and clinical admission days and the number of patients included in this study from 2003 until 2015. (DOCX 19 kb)

Additional file 2: Text file: List of all variables extracted from electronic medical records of included case and control patients. (DOCX $28 \mathrm{~kb}$ )

Additional file 3: Text file: Treatment related variables, categorical, univariate analysis. Variables with an asterisk $\left(^{*}\right)$ were selected for multivariable analysis. (DOCX $37 \mathrm{~kb}$ )

Additional file 4: Text file: Subgroup analysis DiversiLab (bioMérieux) type $A$ and type $B$, univariate analysis. Variables with an asterisk $\left(^{*}\right)$ were selected for multivariable analysis. (DOCX $70 \mathrm{~kb}$ )

Additional file 5: Text file: Subgroup analysis ICU or non-ICU as ward of acquisition of VIM-PA, univariate analysis. Variables with an asterisk (*) were selected for multivariable analysis. (DOCX $83 \mathrm{~kb}$ )

Additional file 6: Text file: Crude odds ratios; control group $1 \& 2$ versus control group $3 \& 4$. Variables with an asterisk $\left(^{*}\right)$ were selected for multivariable analysis. (DOCX 35 kb)

\section{Abbreviations}

Cl: Confidence interval; Erasmus MC: Erasmus MC University Medical Centre; ICUs: Intensive care units; MBL: Metallo- $\beta$-lactamases; MDRPA: Multidrugresistant strains of Pseudomonas aeruginosa; OR: Odds ratio; PCR: Polymerase chain reaction; SDD: Selective digestive tract decontamination; VIM: Verona Integron-encoded metallo- $\beta$-lactamase; VIM-PA: Verona Integron-encoded metallo- $\beta$-lactamase-positive clone of Pseudomonas aeruginosa

\section{Acknowledgments}

We want to thank Laura Frieso MSc (data retrieval), Dr. Dimitris Rizopoulos (statistical advice), Dr. Norbert Vaessen and Dr. Dinis dos Reis Miranda (data retrieval and analysis of preliminary data) for their work and cooperation. We also want to thank employees of the diagnostic laboratory and the infection control practitioners from the Department of Medical Microbiology and Infectious Diseases, and all the healthcare workers involved in the outbreak from the Erasmus MC University Medical Centre, Rotterdam, the Netherlands. The network analysis was presented as a paper poster presentation at the 26th 2016 European Congress of Clinical Microbiology and Infectious Diseases (ECCMID), Amsterdam, the Netherlands, abstract number 1844. The case-control study was presented as a paper poster presentation at the 27th 2017 European Congress of Clinical Microbiology and Infectious Diseases (ECCMID), Vienna, Austria, abstract number 4893.

\section{Funding}

This study did not receive any specific grant from funding agencies in the public, commercial, or not-for-profit sectors.

\section{Availability of data and materials}

The datasets used and/or analysed during the current study are available from the corresponding author on reasonable request.

\section{Authors' contributions}

$A V, J S$ and MV designed and directed the study. AV, MH and IG collected the data. AF performed the statistical analyses. AV, JS, DG and MV analyzed and interpreted the data. All authors were part of drafting the article or revising it critically, and read and approved the final manuscript.

\section{Ethics approval and consent to participate}

Written approval to conduct this study was received from the medical ethics research committee of the Erasmus MC University Medical Centre (Erasmus MC), Rotterdam, the Netherlands (MEC-2015-240). This study is registered in the Dutch National Trial Register (NTR5145).

\section{Consent for publication}

Not applicable.

Competing interests

The authors declare that they have no competing interests.

\section{Publisher's Note}

Springer Nature remains neutral with regard to jurisdictional claims in published maps and institutional affiliations.

\section{Author details}

${ }^{1}$ Department of Medical Microbiology and Infectious Diseases, Erasmus MC University Medical Centre, Rotterdam, The Netherlands. ${ }^{2}$ Department of Adult Intensive Care, Erasmus MC University Medical Centre, Rotterdam, The Netherlands.

Received: 27 October 2017 Accepted: 20 February 2018

Published online: 27 February 2018

References

1. Albiger B, Glasner C, Struelens MJ, Grundmann H, Monnet DL, European Survey of Carbapenemase-Producing Enterobacteriaceae working group. Carbapenemase-producing Enterobacteriaceae in Europe: assessment by national experts from 38 countries, May 2015. Euro Surveill. 2015;20:1-18.

2. Hong DJ, Bae IK, Jang IH, Jeong SH, Kang HK, Lee K. Epidemiology and characteristics of Metallo-beta-lactamase-producing Pseudomonas aeruginosa. Infect Chemother. 2015;47:81-97. 
3. Carmeli Y, Troillet N, Karchmer AW, Samore MH. Health and economic outcomes of antibiotic resistance in Pseudomonas aeruginosa. Arch Intern Med. 1999;159:1127-32.

4. Stover CK, Pham XQ, Erwin AL, Mizoguchi SD, Warrener P, Hickey MJ, Brinkman FSL, Hufnagle WO, Kowalik DJ, Lagrou M, et al. Complete genome sequence of Pseudomonas aeruginosa PAO1, an opportunistic pathogen. Nature. 2000;406:959-64.

5. Suarez C, Pena C, Gavalda L, Tubau F, Manzur A, Dominguez MA, Pujol M, Gudiol F, Ariza J. Influence of carbapenem resistance on mortality and the dynamics of mortality in Pseudomonas aeruginosa bloodstream infection. Int J Infect Dis. 2010;14(Suppl 3):e73-8.

6. Zhang Y, Chen XL, Huang AW, Liu SL, Liu WJ, Zhang N, Lu XZ. Mortality attributable to carbapenem-resistant Pseudomonas aeruginosa bacteremia: a meta-analysis of cohort studies. Emerg Microbes Infect. 2016;5:e27.

7. Walsh TR, Toleman MA, Poirel L, Nordmann P. Metallo-beta-lactamases: the quiet before the storm? Clin Microbiol Rev. 2005;18:306-25.

8. Walsh TR. Emerging carbapenemases: a global perspective. Int J Antimicrob Agents. 2010;36(Suppl 3):S8-14.

9. Van der Bij AK, Van der Zwan D, Peirano G, Severin JA, Pitout JD, Van Westreenen M, Goessens WH, Group M-PSS. Metallo-beta-lactamaseproducing Pseudomonas aeruginosa in the Netherlands: the nationwide emergence of a single sequence type. Clin Microbiol Infect. 2012;18: E369-72.

10. Hota S, Hirji Z, Stockton K, Lemieux C, Dedier H, Wolfaardt G, Gardam MA. Outbreak of multidrug-resistant Pseudomonas aeruginosa colonization and infection secondary to imperfect intensive care unit room design. Infect Control Hosp Epidemiol. 2009;30:25-33.

11. Otter JA, Vickery K, Walker JT, deLancey Pulcini E, Stoodley P, Goldenberg SD, Salkeld JA, Chewins J, Yezli S, Edgeworth JD. Surface-attached cells, biofilms and biocide susceptibility: implications for hospital cleaning and disinfection. J Hosp Infect. 2015;89:16-27.

12. Van der Bij AK, Van Mansfeld R, Peirano G, Goessens WH, Severin JA, Pitout JD, Willems $R$, Van Westreenen M. First outbreak of VIM-2 metallo-betalactamase-producing Pseudomonas aeruginosa in The Netherlands: microbiology, epidemiology and clinical outcomes. Int J Antimicrob Agents. 2011;37:513-8

13. Voor In 't Holt AF, Severin JA, Lesaffre EM, Vos MC. A systematic review and meta-analyses show that carbapenem use and medical devices are the leading risk factors for carbapenem-resistant Pseudomonas aeruginosa. Antimicrob Agents Chemother. 2014;58:2626-37.

14. de Smet AM, Kluytmans JA, Cooper BS, Mascini EM, Benus RF, van der Werf TS, van der Hoeven JG, Pickkers P, Bogaers-Hofman D, van der Meer NJ, et al. Decontamination of the digestive tract and oropharynx in ICU patients. N Engl J Med. 2009:360:20-31.

15. Verfaillie CJ, Bruno MJ, Voor in 't Holt AF, Buijs JG, Poley JW, Loeve AJ, Severin JA, Abel LF, Smit BJ, de Goeij I, Vos MC. Withdrawal of a noveldesign duodenoscope ends outbreak of a VIM-2-producing Pseudomonas aeruginosa. Endoscopy. 2015:47:493-502.

16. Shannon P, Markiel A, Ozier O, Baliga NS, Wang JT, Ramage D, Amin N, Schwikowski B, Ideker T. Cytoscape: a software environment for integrated models of biomolecular interaction networks. Genome Res. 2003:13:2498-504.

17. Knoester M, de Boer MG, Maarleveld JJ, Claas EC, Bernards AT, de Jonge E, van Dissel JT, Veldkamp KE. An integrated approach to control a prolonged outbreak of multidrug-resistant Pseudomonas aeruginosa in an intensive care unit. Clin Microbiol Infect. 2014;20:0207-15.

18. Kenters N, Huijskens EG, Meier C, Voss A. Infectious diseases linked to crosscontamination of flexible endoscopes. Endosc Int Open. 2015;3:E259-65.

19. Muscarella LF. Risk of transmission of carbapenem-resistant Enterobacteriaceae and related "superbugs" during gastrointestinal endoscopy. World I Gastrointest Endosc. 2014;6:457-74.

20. von Elm E, Altman DG, Egger M, Pocock SJ, Gotzsche PC, Vandenbroucke $J P$, Initiative S. The Strengthening the Reporting of Observational Studies in Epidemiology (STROBE) statement: guidelines for reporting observational studies. Lancet. 2007;370:1453-7.

21. Brossier F, Micaelo M, Luyt CE, Lu Q, Chastre J, Arbelot C, Trouillet JL, Combes A, Rouby JJ, Jarlier V, Aubry A. Could the DiversiLab(R) semiautomated repetitive-sequence-based PCR be an acceptable technique for typing isolates of Pseudomonas aeruginosa? An answer from our experience and a review of the literature. Can J Microbiol. 2015;61:903-12.

\section{Submit your next manuscript to BioMed Central and we will help you at every step:}

- We accept pre-submission inquiries

- Our selector tool helps you to find the most relevant journal

- We provide round the clock customer support

- Convenient online submission

- Thorough peer review

- Inclusion in PubMed and all major indexing services

- Maximum visibility for your research

Submit your manuscript at www.biomedcentral.com/submit
C Biomed Central 